\title{
New Look on Ureterocolic Diversion with Adjuvant Radiotherapy; SECI (South Egypt Cancer Institute) Experience
}

\author{
Badawy M. Ahmed1 ${ }^{*}$, Ebrahim Aboeleuon1, Ahmed M. Abdel-Rahim², Osama M. Abd Elbadee \\ ${ }^{1}$ Surgical Oncology Department, South Egypt Cancer Institute, Assiut University, Assiut, Egypt \\ ${ }^{2}$ Urology Unit, South Egypt Cancer Institute, Assiut University, Assiut, Egypt \\ ${ }^{3}$ Radiotherapy Department, South Egypt Cancer Institute, Assiut University, Assiut, Egypt \\ Email: ^badawy_znatyy@yahoo.co.uk
}

How to cite this paper: Ahmed, B.M., Aboeleuon, E., Abdel-Rahim, A.M. and Abd Elbadee, O.M. (2018) New Look on Ureterocolic Diversion with Adjuvant Radiotherapy; SECI (South Egypt Cancer Institute) Experience. Journal of Cancer Therapy, 9, 898-906.

https://doi.org/10.4236/jct.2018.911074

Received: September 27, 2018

Accepted: November 17, 2018

Published: November 20, 2018

Copyright $\odot 2018$ by authors and Scientific Research Publishing Inc. This work is licensed under the Creative Commons Attribution International License (CC BY 4.0).

http://creativecommons.org/licenses/by/4.0/ cc) (i) Open Access

\begin{abstract}
Background: Ureterosigmoidostomy was the first form of continent urinary diversion and had broad popularity during the first half of the 20th century. Primary enthusiasm was followed by disappointment when serious problems such as pyelonephritis, electrolyte imbalance, renal calculi and renal function deterioration become evident. In the 1950s these life threatening complications led to avoid this urinary diversion in favor of uretro-intestinal conduits. Objectives: Our aim was to evaluate our experience in ureterocolic shunt after radical cystectomy for bladder cancer. Methodology: This study was conducted in surgical oncology department, South Egypt cancer institute, Assiut university; in the period from January 2012 to January 2017 and including 115 patients ( 75 males \& 40 females). Results: This is retrospective study including 115 patients ( 75 males \& 40 females). Operative time was $130 \mathrm{mi}$ nutes ranging between 2 to 2.5 hours. Average blood loss was $450 \mathrm{ml}$. After removal of rectal tube all patients were continent except 15 patients who were improved after 1 - 3 days. Within a month 12 patients had night incontinence and 5 patients had day time incontinence. After that day and night continence gradually improved in all patients except two females who had persistent night soiling and was in need for night time rectal tube. Conclusion: Ureterosigmoidostomy regains the interest of surgical oncology and urologist because of its simplicity and absence of appliance as many patients refusing cutaneous stoma and others are not suitable for orthotopic substitutes.
\end{abstract}

\section{Keywords}

Ureterocolic Shunt, Ureterosigmoidostomy, Continent Diversion 


\section{Introduction}

Ureterosigmoidostomy was the first form of continent urinary diversion and had broad popularity during the first half of the 20th century. Primary enthusiasm was followed by disappointment when serious problems such as pyelonephritis, electrolyte imbalance, renal calculi, and renal function deterioration become evident. In the 1950s these life threatening complications led to avoid this urinary diversion in favor of uretro-intestinal conduits [1].

The complications of the ureterosigmoidostomy have been well detailed, including ascending infection, obstruction, calculi, electrolyte imbalance, [2] [3] [4] [5] and neoplasms [6] [7] [8]. While Lapides proposed that the hyperchloremic acidosis resulted from pyelonephritis in patients with normal renal function, Stamey demonstrated that colon reabsorption alone could produce this, even in patients with normal renal function [3] [4]. When hydronephrosis and/or pyelonephritis result in renal damage, then the colon chloride absorption load readily exceeds the kidney's excretory capability, resulting in acidosis.

\section{Patients and Methods}

This study was conducted in surgical oncology department and radiation therapy unit, South Egypt cancer institute, Assiut University; in the period from January 2012 to January 2017 and including 115 patients (75 males \& 40 females). Inclusion criteria were as follows: histologically confirmed invasive bladder cancer, operable and medically fit patients. Exclusion criteria were; metastatic disease, patient refusal and unfit patients.

Study parameters include demographic details, body mass index (BMI), operative time, length of hospital stay (LOS), post operative morbidity and mortality, histopathological data, adjuvant treatment, Renal function follow up, continence evaluation, recurrence and colonic tumor development.

Criteria of selection and preparation

Patients were considered eligible for this diversion if they were:

- Age should less than 70 years (as sphincter competence decreased with increased age).

- No history of diabetes mellitus or neurological problems.

- Sufficient renal function (creatinine level less than $1.5 \mathrm{mg} / \mathrm{ml}$ ) to compensate for potential hyperchloremic acidosis.

- No colorectal diseases.

- Bilateral normal upper urinary tract on IVU to allow anti-reflux implantation of the ureters.

- No previous colonic surgery or irradiation.

A rough clinical test to evaluate anal continence is by asking the patient to contract his anal sphincter against the examiner finger. By this simple method we can evaluate tone and power of anal sphincter. Another test by asking the patients to retain 350 - $400 \mathrm{~cm}$ water enema for 4 hours with normal daily activity, urgency or insensible soiling means weak anal tone. 
Colonic preparation was done using mechanical preparation (low residue diet and rectal enema) and chemical preparation using intestinal antiseptics and fortranse sachets).

All the procedures were performed after obtaining informed consent from the patients following the explanation of the surgical and the oncological risks.

Our study was approved by the ethical committee at South Egypt Cancer Institute.

\subsection{Surgical Technique}

Radical cystoprostatectomy or anterior pelvic exentration for females was performed in the usual way.

Uerterosigmoidostomy was performed by making a longtudinal incision in the antimesentric taenia coli up to the mucosa at the junction of sigmoid and rectum and extended upward for $5 \mathrm{~cm}$. implantation of the ureter started by tunneling of both ureters retroperitonealy and submucosaly and fixed to serosa by stay sutures after pulling up of the ureters through the mucosa they were fixed by umblication fashion using $3 / 0$ polygalactin sutures (one ureter is implanted in level higher than the other) to secure the ureteral implantation $8 \mathrm{~F}$ stents were placed and led down with the rectal tube and fixed by sutures in the perianal skin. Colostomy was closed in transverse manner (mucosa by continues $3 / 0$ polygalactin sutures seromusclosa by interrupted $2 / 0$ silk sutures). The abdomen is drained by 2 tubal drains in the pelvis.

\subsection{Postoperative}

Patients started oral fluids after 3 days from operation for 3 days then semisolids for another 3 days then solids.

All patients started prophylactic alkalization (sodium bicarbonate) when they start oral feeding.

Rectal tube was removed after starting semisolid feeding.

Ureteric stents were removed after 2 weeks after that by 2 days abdominal drains were removed when confirming no leakage.

\subsection{Adjuvant Radiation Therapy}

In our study, all patients received postoperative external beam radiation therapy at radiation therapy department of south Egypt cancer institute. After a median postoperative period of about 28 days, patients were referred to the radiation therapy unit, where computed tomography (CT) simulation was done on the pelvis in supine position with a $1 \mathrm{~mm}$ cut thickness. Using a three dimensional treatment planning system (TPS_XIO version), 3D plan performed using 3, 4, or 6 coplanar and non-coplanar fields. The clinical target volume (CTV) included the postoperative bed and the pelvic nodes (internal iliac, external iliac, and obturator lymph nodes). Most cases needs wedge as a beam modifier especially in the lateral fields. The rectum and femoral heads was the most common organ at 
risk. Patients were treated using multi-energy linear accelerator, where $15 \mathrm{MV}$ was the most energy used in all fields, but also $6 \mathrm{MV}$ energy was used mainly in the anterior field and thin patients. All patients received 50 Gray radiation dose prescribed to the CTV, 5 fractions weekly for 5 weeks.

\subsection{Follow up}

Patients were seen every 3 months in the first 3 years and every 6 months thereafter. Follow up included full continent history (day and night), symptoms of renal problems as infection or dysfunction in addition of symptoms of underlying malignancy, routine abdominal sonar, chest $\mathrm{x}$-ray, renal and liver function test. C.T pelvi-abdomen was done every 6 months in the first 2 years and every year thereafter. The main items of interest were operative complications, effects on upper urinary and continence.

\subsection{Statistical Analysis}

Mean, range and percentage were used to estimate parameters under the study.

\section{Results}

This is retrospective study including 115 patients (75 males \& 40 females) who were admitted in surgical oncology department in south Egypt Cancer Institute-Assiut University for radical cystectomy. Operative time was 130 minutes ranging between 2 to 2.5 hours.

Operative time included cystoprostatectomy or anterior pelvic excentration, iliac lymphadenectomy and uretersigmoidostomy.

Average blood loss was $450 \mathrm{ml}$. After removal of rectal tube all patients were continent except 15 patients who were improved after 1 - 3 days. Within a month 12 patients had night incontinence and 5 patients had day time incontinence. After that day and night continence gradually improved in all patients except two females who had persistent night soiling and was in need for night time rectal tube.

Early postoperative complications as follows:

- 6 patients ( 4 males $\& 2$ females) had urinary leakage (<than $500 \mathrm{ml} /$ day) and were managed conservatively by continuous drainage for $7-18$ days which was success in decreasing the amount of drainage till complete cessation.

- 4 patients developed ilio-femoral DVT in postoperative day 7 and treated by anticoagulants. While ilio-femoral DVT and massive pulmonary embolism was developed in 2 patients.

- Adhesive intestinal obstruction was developed in 2 patients in postoperative day 20 and 22, which was treated conservatively in one patient and by, exploration with adhesiolysis in the other one and had smooth postoperative course.

- Ten patients had wound infection; 6 of them were suffering from leakage in addition to wound sepsis. 
Post operative mortality was present in 3 patients 2 of them developed DVT and pulmonary embolism and died in postoperative day 3. Other patient suffering from leakage, peritonitis, wound sepsis and dehiscence and died from multi-organ failure after 18 days.

Upper urinary tract did not change without any back pressure signs in 20 patients according to sonographic and C.T findings.

Mean follow up was (38 months) ranged from 1 year to 5 years. During follow up; one patient developed sever pyelonephritis which needs hospitalization and treated by antibiotics, rectal tube and diuretics and asking the patient to evacuated his rectum frequently. Also one patient developed marked acidosis and was in need for hospitalization, after treatment and correction of general condition; patient is encouraged to evacuate her rectum frequently and increase the dose of alkalinizing drug.

Recurrence was found in (9\%) while new cancer formation was present in 3 cases in the form of adenocarcinoma (one case was treated by resection anastomosis and reimplantation of the ureters with covering iliostomy which closed later on the other case was treated by rectal bladder and terminal colostomy, the last one is treated by anterior resection of Dixon and ileal conduit (Table 1).

\section{Discussion}

The objectives of urinary diversion not only to keep kidney function normal but also to give the patient good quality of life and to some extent normal social activity. Ureterosigmoidostoy is one of the simplest and oldest methods of continent urinary diversions.

Despite of losing the affinity of urologists to do it because of its complications; in our institute we are still using it with good results especially when patient refusing non continent diversion or not candidate for other continent methods. In general almost all patients refusing cutaneous stoma because of unavailability of appliance, financial cost and urineferous odor. Many studies were evaluating results and its complications of ureterosigmoidostomy and its modifications. In our study early complications were presented in $23(20 \%)$ patients while in other studies El-Mekresh et al. [9]; 8 (14\%), Gerhaz et al. [10]; 4 (11.7\%), Obek et al. [11]; 2 (3.3\%) and Omaya [12]; 6 (28.6\%). Late complications (metabolic acidosis, upper urinary dilatation and pyelonephritis) in our study were $2.6 \%, 6 \%$ and 3.5\% respectively compared to other studies El-Mekresh et al. [9]; (0\%, 5.3\% and $3.5 \%)$, Gerhaz et al. [10]; (5.8\%, 2.9\% and 2.9\%), Obek et al. [11]; (6\%, 5\% and $8 \%)$ and Omaya [12]; (4.7\%, 9.5\% and 4.7\%). In this study only 2 (1.7\%) female patients had persistent night incontinence in comparison to other studies El-Mekresh et al. [9]; 4 (7\%), Gerhaz et al. [10]; 1 (2.9\%), Obek et al. [11]; 1 (1.6\%) and Omaya [12]; 1 (4.7\%). Recently, it became evident that most of these complications are essentially due to high-pressure within the intact sigmoid colon and rectum. Functional studies proved that the pressure due to bowel contractions at the anus exceeds $100 \mathrm{~cm} \mathrm{H}_{2} \mathrm{O}$, and during defecation pressure can reach up to $200 \mathrm{~cm} \mathrm{H}_{2} \mathrm{O}$ [13]. Detubularisation of the sigmoid colon and rectum 
Table 1. All parameters of the study.

\begin{tabular}{|c|c|c|}
\hline & Mean & Range or percent \\
\hline \multicolumn{3}{|l|}{$\underline{\text { Patient characters: }}$} \\
\hline - Age. & $55 \mathrm{y}$ & $45-60$ \\
\hline - Sex ratio $\mathrm{M}: \mathrm{F}$ & $75: 40$ & \\
\hline - Positive margin: & 5 & $4.3 \%$ \\
\hline - $\quad$ BMI. & 24.5 & $21.8-27.2$ \\
\hline - Path: & & \\
\hline - Sq.c.c. & 40 & $35 \%$ \\
\hline - T.c.c. & 60 & $52 \%$ \\
\hline - Adenocacinoma. & 5 & $4.3 \%$ \\
\hline - Others. & 10 & $8.7 \%$ \\
\hline \multicolumn{3}{|l|}{ Staging: } \\
\hline$-\quad$ Stage II & 35 & $30.5 \%$ \\
\hline - Stage III & 80 & $69.5 \%$ \\
\hline \multicolumn{3}{|l|}{ Operative: } \\
\hline - Op. time. & $130 \mathrm{~min}$ & $120-150 \mathrm{~min}$ \\
\hline - Bl. loss. & $450 \mathrm{ml}$ & $300-500 \mathrm{ml}$ \\
\hline \multicolumn{3}{|l|}{ Early Post op. compl: } \\
\hline ^Urinary leakage. & 6 cases & $5.2 \%$ \\
\hline${ }^{\star}$ Intestinal obstruction. & 2 cases & $1.7 \%$ \\
\hline${ }^{\star} \mathrm{DVT} \pm$ pulmonary embolism. & 5 cases & $4.3 \%$ \\
\hline ^Wound sepsis. & 10 cases & $8.7 \%$ \\
\hline Hosp. stay. & 11 days & $10-31$ days \\
\hline Mortality. & 3 cases & $2.6 \%$ \\
\hline \multicolumn{3}{|l|}{$\underline{\text { Late complications: }}$} \\
\hline${ }^{*}$ Metabolic acidosis & 3 cases & $2.6 \%$ \\
\hline ^Pyelonephritis. & 4 cases & $3.5 \%$ \\
\hline *Upper urinary dilatation. & 7 cases & $6 \%$ \\
\hline \multicolumn{3}{|l|}{ Recurrence: } \\
\hline${ }^{\star}$ Local. & 5 cases & $4.3 \%$ \\
\hline ^Systemic. & 2 cases & $1.7 \%$ \\
\hline${ }^{*}$ Both. & 3 cases & $2.6 \%$ \\
\hline Colonic adenocarcinoma. & 3 cases & $2.6 \%$ \\
\hline \multicolumn{3}{|l|}{ Incontinence: } \\
\hline \multicolumn{3}{|l|}{${ }^{\star}$ first month: } \\
\hline - day & 5 cases & \\
\hline - night & 12 cases & \\
\hline \multicolumn{3}{|l|}{$*^{\text {nd }}$ month: } \\
\hline - day & 3 cases & \\
\hline - night & 7 cases & \\
\hline \multicolumn{3}{|l|}{ *>2 months: } \\
\hline - day & 1 case & \\
\hline - night & 4 cases & \\
\hline${ }^{*}$ persistent. & 2 case night incontinence only & $1.7 \%$ \\
\hline
\end{tabular}

M:F (Male:Female), BMI (body mass index), path (pathology), sq.c.c (squamous cell carcinoma, t.c.c (transitional cell carcinoma), Op. time (operative time), Bl. loss (blood loss), Hosp. stay (hospital stay). N.B all patients receiving adjuvant radiation therapy. 
eliminate the mass contractions and high-pressure making low-pressure reservoir allowing for better continence and protection of the upper urinary tract than what achieved by usual ureterosigmoidostomy. Secondary malignancy after ureterocolic anastomosis is a well known complication and incidence not affected by different modifications [14]. The average time interval between development of tumors and ureterosigmoidostomy is 20 to 26 years, with a range of 2 - 53 years [15] [16] [17]. While in our study the average time interval was 2 - 3 years. In fact it is not important in elderly patients undergoing cystectomy for carcinoma of the urinary bladder as time interval is long. Long term follow up of alternative methods of urinary diversion revealed a considerable complications rate including similar repeated pyelonephritis, upper urinary dilation and many stomal complications as hernia, stricture, prolapse and peristomal skin changes [18].

The addition of radiation therapy for all patients was derived from many Egyptian clinical trials that demonstrated the disease free survival benefits gained from the addition of radiation therapy after radical cystectomy especially for T3, T4a. Zaghloul et al. evaluated Two hundred thirty-six patients with P3a, $\mathrm{P} 3 \mathrm{~b}$, or $\mathrm{P} 4 \mathrm{a}$ tumors were randomized in two phases into three groups: 1) no further treatment (83 patients); 2) postoperative radiotherapy multiple daily fractionation (MDF), using 3 daily fractions of $1.25 \mathrm{~Gy}$ each, with $3 \mathrm{hr}$ between fractions, up to a total dose of $37.5 \mathrm{~Gy}$ in 12 days (75 patients); and 3) postoperative radiotherapy conventional fractionation (CF), for a total dose of $50 \mathrm{~Gy} / 5$ weeks (78 patients). The 5-year disease-free survival (DFS) rates amounted to 49 and $44 \%$ in MDF and CF postoperative radiotherapy groups, respectively, compared to $25 \%$ in the cystectomy-alone group. The 5 -year local control rates were $87 \%$ and $93 \%$ for those treated with multiple daily fractionations and conventional fractionation while it was $50 \%$ in the surgery-alone group. The local control in our study were $93.1 \%$ which is similar to that reported by Zaghloul et al. [19].

\section{Conclusion}

Ureterosigmoidostomy regains the interest of surgical oncology and urologist because of its simplicity and absence of appliance as many patients refusing cutaneous stoma and others are not suitable for orthotopic substitutes. Refinements in the surgical techniques, improved antibiotic treatment, alkalizing agents and suture material, anti-reflux implantation of the ureters, detubularisation and reconfiguration of the sigmoid colon and/or rectum (by closing the colon transversely in our study or as Mainz modification in other studies) making low-pressure reservoir all of these making ureterosigmoidostomy safe diversion with good continence and acceptable and easily manageable complications especially in our sociality. In spite of early encouraging results, to confirm our results we are in need for longer time of follow up.

\section{Conflicts of Interest}

We have no conflicts of interest or financial ties to disclose. 


\section{References}

[1] Clarke, B.G. and Leadbetter, W.F. (1955) Ureterosigmoidostomy: Uollective Review of Results in 2897 Reported Cases. The Journal of Urology, 73, 999-1007. https://doi.org/10.1016/S0022-5347(17)67512-8

[2] Zincke, H. and Segura, J.W. (1975) Ureterosigmoidostomy: Critical Review of 173 Cases. The Journal of Urology, 113, 324. https://doi.org/10.1016/S0022-5347(17)59472-0

[3] Lapides, J. (1951) Mechanism of Electrolyte Imbalance Following Ureterosigmoid Transplantation. Surgery, Gynecology \& Obstetrics, 93-691.

[4] Stamey, T.A. (1956) The Pathogenesis and Implications of the Electrolyte Imbalance in Ureterosigmoidostomy. Surgery, Gynecology \& Obstetrics, 103-736.

[5] Wilkinson, A.W. (1954) Biochemical Disturbances after Transplantation of the Ureters. Postgraduate Medical Journal, 30-405.

[6] Sorriyaarchchi, G.S., Johnson, R.O. and Carbone, P.P. (1977) Neoplasms of the Large Bowel Following Ureterosigmoidostom. The Archives of Surgery, 112-1174.

[7] Rivard, J.Y., Bedard, A. and Dionne, L. (1975) Colonic Neoplasms Following Ureterosigmoidostomy. The Journal of Urology, 113-781.

[8] Shapiro, A., et al. (1979) Carcinoma of Colon after Ureterocolic Anastomosis. Urology, 13-617.

[9] El-Mekresh, M.M., Hafez, A.T., Abol-Enein, H. and Ghoneim, M.A. (1997) Double Folded Rectosigmoid Bladder with a New Urterocolic Antireflux Technique. The Journal of Urology, 157, 2085-2089. https://doi.org/10.1016/S0022-5347(01)64681-0

[10] Gerhaz, E.W., Kohl, U.N., Weingartner, K., Kleinhans, B.J., Mekelos, M.D. and Riedmiller, H. (1998) Experience with the Mainze Modification of Ureterosigmoidostomy. British Journal of Surgery, 85, 1512-1516. https://doi.org/10.1046/j.1365-2168.1998.00904.x

[11] Obek, C., Kural, A.R., Ataus, S., Coskuner, E., Demikesen, O., Citici, A., Onder, A.U. and Solok, V. (2001) Complications of the Mainz Pouch II (Sigma Rectal Pouch). European Urology, 39, 204-211. https://doi.org/10.1159/000052437

[12] Nassar, O. (2002) Mainz II Pouch: A Simple Continent Urinary Diversion after Cystectomy. Journal of the Egyptian National Cancer Institute, 14, 267-274.

[13] Fisch, M., Wammack, R. and Hohenfellner, R. (1996) The Sigma Rectum Pouch (Mainz Pouch II). World Journal of Urology, 14, 68-72. https://doi.org/10.1007/BF00182560

[14] Stein, R., Fisch, M., Stockle, M. and Hohenfellne, R. (1995) Urinary Diversion in Bladder Exstrophy and Incontinent Epispadias: 25 Years of Experience. The Journal of Urology, 154, 1177-1181. https://doi.org/10.1097/00005392-199509000-00093

[15] Koo, H.P., Avolio, L. and Duckett, J.W.J. (1996) Long-Term Results of Ureterosigmoidostomy in Children with Bladder Exstrophy. The Journal of Urology, 156, 2037-2040. https://doi.org/10.1016/S0022-5347(01)65429-6

[16] Husmann, D.A. and Spence, H.M. (1990) Current Status of Tumor of the Bowel Following Ureterosigmoidostomy: A Review. The Journal of Urology, 144, 607-610. https://doi.org/10.1016/S0022-5347(17)39535-6

[17] Harford, F.J., Fazio, V.W., Epstein, L.M. and Hewitt, C.B. (1984) Rectosigmoid Carcinoma Occurring after Ureterosigmoidostomy. Diseases of the Colon \& Rectum, 27, 321-324. https://doi.org/10.1007/BF02555645

[18] Hendren, W.H. and Radoulos, D. (1983) Complications of Ileal Loop and Colon 
Conduit Urinary Diversion. Urologic Clinics of North America, 10, 451-471.

[19] Zaghloul, M.S., Awwad, H.K., Akoush, H.H., Omar, S., Soliman, O. and el Attar, I. (1992) Postoperative Radiotherapy of Carcinoma in the Belharzial Bladder: Improved Disease Free Survival through Improving Local Control. International Journal of Radiation Oncology, Biology, Physics, 23, 511-517. 